\title{
Desenvolvimento, produtividade e qualidade dos frutos da videira em consórcio com culturas de cobertura
}

Development, productivity and quality of the fruits of the vine in consortium with cover crops

\section{Luiz Fernandes Cardoso Campos ${ }^{*}$, Camila Meira de Abreu Campos ${ }^{2}$, Leonardo Santos Collier ${ }^{1}$, Alexsander Seleguini ${ }^{3}$}

Submissão: 01/03/2017 / Aceite: 12/05/2017

\section{RESUMO}

A utilização de cobertura vegetal permanente ou parcial do solo nos vinhedos pode influenciar a produção e a qualidade da uva. Assim, o objetivo desse trabalho foi avaliar o desenvolvimento da videira a produtividade, bem como as características qualitativas da uva 'Isabel', em consórcio com plantas de cobertura do solo. O experimento foi conduzido no município de Itapuranga, GO, e consistiu em seis tratamentos estabelecidos em delineamento de blocos ao acaso, no esquema fatorial $3 \times 2$, em cinco repetições. O primeiro fator consistiu em espécies de plantas cobertura do solo: feijão-de-porco (Canavalia ensiformis L. DC), lab-lab (Dolichos lab lab L.) e plantas espontâneas. No segundo fator, foram duas épocas de poda na cultura da videira, realizadas com base na semeadura das plantas de cobertura. Ou seja, a primeira época de poda na videira foi realizada 25 dias após a semeadura (DAS) das plantas de cobertura e a segunda época de poda na videira foi realizada aos 55 DAS. Em três ciclos de cultivo, as plantas de cobertura do solo consorciadas com a videira, não influenciam as variáveis morfológicas, a produtividade, as variáveis associadas a produtividade e as características qualitativas da uva. Diferentes épocas de poda influenciam a produtividade e as variáveis associadas na cultura da videira. A poda aos 25 dias após a semeadura, das plantas de cobertura, apresenta melhores resultados para as variáveis morfológicas e características qualitativas da uva. Portanto para as condições locais e pelo tempo avaliado, o uso de plantas de cobertura não influenciaram a produção das videiras bem como a qualidade da uva. Entretanto as épocas de poda podem afetar o desenvolvimento da videira, refletindo em sua produtividade e qualidade.
PALAVRAS-CHAVE: Vitis labrusca L., Canavalia ensiformis L. DC, Dolichos lab lab L., viticultura tropical, época de poda, cultivar Isabel.

\section{ABSTRACT}

The use of permanent or partial vegetative cover of the soil in the vineyards can influence the production and the quality of the grape. Thus, the objective of this work was to evaluate the development of the grapevine productivity as well as the qualitative characteristics of 'Isabel' grape, in consortium with soil cover plants. The experiment was conducted in the municipality of Itapuranga, GO, and consisted of six treatments established in a randomized block design, in a $3 \times 2$ factorial scheme, in five replications. The first factor consisted of a plant species cover the soil: Jack Beans (Canavalia ensiformis L. DC), lab-lab (Dolichos lab $l a b$ L.) and spontaneous plants. In the second factor, there were two pruning seasons of the grapevine crop, based on the sowing of the cover crops. In other words, the first pruning season in the vine was performed 25 days after sowing (DAS) of the cover plants and the second pruning season in the vine was performed at 55 DAS. In three crop cycles, the soil cover plants consortium with the grapevine does not influence the morphological variables, the productivity, the variables associated with the productivity and the qualitative characteristics of the grape. Different times of pruning influence the productivity and the associated variables in the grape crop. The pruning at 25 days after sowing of the cover plants presented better results for the morphological variables and qualitative characteristics of the grape. Therefore, for the local conditions and for the evaluated time, use of hedge plants did not influence the production of

${ }^{1}$ Universidade Federal de Goiás, Goiânia, GO, Brasil.

${ }^{2}$ Universidade Estadual de Goiás, Anápolis, GO, Brasil.

${ }^{3}$ Universidade Federal do Triângulo Mineiro, Iturama, MG, Brasil.

*Autor para correspondência <luizfernandescampos@hotmail.com> 
the vines as well as the quality of the grape. However pruning times can affect the development of the vine, reflecting its productivity and quality.

KEYWORDS: Vitis labrusca L., Canavalia ensiformis L. DC, Dolichos lab lab L., tropical viticulture, pruning season, cultivate Isabel.

\section{INTRODUÇÃO}

A viticultura tropical é típica de regiões em que as temperaturas mínimas não são suficientemente baixas para induzir a videira à dormência. Portanto, seu crescimento é contínuo, havendo a possibilidade de obtenção de duas ou mais colheitas por ano (CAMARGO et al. 2012). O que permite o escalonamento da colheita e consequente comercialização dos frutos em períodos de preços mais atrativos (SILVA et al. 2006). Nesse contexto, a viticultura surge com enorme potencial econômico para o Estado de Goiás, Brasil, assim como na região do Cerrado (FARIA et al. 2013).

Em regiões tradicionais de viticultura temperada ou subtropical, o manejo do solo utilizando coberturas vegetais tem sido uma opção para os produtores manterem a sustentabilidade do parreiral. As plantas de cobertura, geralmente, são cultivadas nas entrelinhas das videiras e até mesmo nas faixas das linhas, com o objetivo de proteger a superfície do solo, evitar a erosão, regulação do crescimento da videira, melhoria da fertilidade do solo, na estrutura e na capacidade de retenção de água, aumento da diversidade biológica do solo, supressão de plantas daninhas, etc. (COLUGNATI et al. 2004, MONTEIRO et al. 2008). O consórcio de plantas de cobertura é uma importante ferramenta para o produtor, entretanto são escassos na literatura trabalhos relacionados ao comportamento dessas plantas em sistemas de cultivo da videira em região tropical (CAMPOS et al. 2015).

Algumas caraterísticas químicas são responsáveis pelo sabor da uva, como sólidos solúveis e acidez, e precisam ter seus valores avaliados com a finalidade de caracterizar o fruto como um todo, já que estas caraterísticas podem sofrer alterações devido as diferentes condições ambientais e de manejo (NEIS et al. 2010). Também, o $\mathrm{pH}$ possui uma grande importância nas características físico-químicas, biológicas e sensoriais dos vinhos, sendo o $\mathrm{pH}$ e a acidez titulável as duas propriedades mais importantes no equilíbrio ácido de sucos de frutas, especialmente no mosto de uva (DAUDT \& FOGAÇA 2008).

LOPES et al. (2008) verificaram redução no crescimento vegetativo da videira, com uso de plantas de cobertura na entrelinha, esse efeito foi positivo sobre a composição da uva, reduzindo a acidez titulável e o aumento da baga, fenóis totais e antocianinas. FARIA et al. (2004) verificaram que embora a adubação verde, com Crotalaria juncea e feijão-de-porco, tenha proporcionado uma melhoria nas características químicas do solo, não se verificou efeitos positivos consistentes na produtividade e qualidade da uva ao longo das oito safras avaliadas, no Submédio São Francisco. WUTKE et al. (2004) concluíram que a substituição da cobertura morta de capim, tradicionalmente utilizada nas ruas do parreiral, pelo cultivo intercalar de aveia-preta e/ou de chícharo e/ou de tremoço, no outono-inverno, seguidos de mucuna-anã, na primavera-verão, não alteram de forma negativa os teores de sólidos solúveis, $\mathrm{pH}$ e acidez titulável dos frutos de videira Niágara Rosada.

A expansão da viticultura brasileira tem levado os produtores cada vez mais a se adequarem às novas técnicas e manejo da cultura (ABREU et al. 2017). Entretanto, há uma grande carência de informação sobre a influência das plantas de cobertura do solo, nas condições edafoclimáticas do Cerrado.

Assim, o objetivo desse trabalho foi avaliar o desenvolvimento da videira a produtividade, bem como as características qualitativas da uva 'Isabel', em consórcio com plantas de cobertura do solo.

\section{MATERIAL E MÉTODOS}

O estudo foi realizado no município de Itapuranga, GO, na Fazenda Capoeira Grande (15³4'32”S; 5000'31”O; 635 m). Segundo Köppen, o clima predominante na região é do tipo Aw, clima tropical com estação seca de Inverno. O solo da área experimental foi classificado como Latossolo Vermelho distrófico (EMBRAPA 2013), as características químicas e físicas na camada de $0,0-$ 0,20 $\mathrm{m}$ de profundidade, são apresentadas na Tabela 1.

A área experimental foi formada pela videira cultivar 'Isabel', enxertada sobre porta-enxerto IAC 572 'Jales', em sistema de condução tipo latada, com espaçamento de 2,5 x 2,5 m. Na ocasião da implantação do experimento o parreiral apresentava a idade de dois anos após a enxertia. O parreiral foi irrigado por microaspersão, utilizando-se emissores 
com vazão de $70 \mathrm{~L} \mathrm{~h}^{-1}$, espaçados em $5 \times 5 \mathrm{~m}$, com $100 \%$ de área molhada.

Os dados climáticos da região foram obtidos de estação meteorológica da Cidade de Goiás, GO, no ano de 2013 e início de 2014 (Figura 1).

O experimento consistiu em seis tratamentos estabelecidos em delineamento de blocos ao acaso, no esquema fatorial $3 \times 2$, em cinco repetições. $\mathrm{O}$ primeiro fator consistiu em plantas cobertura do solo: feijão-de-porco (Canavalia ensiformis L. DC), lablab (Dolichos lab lab L.) e plantas espontâneas. No segundo fator, foram duas épocas de poda na cultura da videira, realizadas com base na semeadura das plantas de cobertura. Ou seja, a primeira época de poda na videira foi realizada 25 dias após a semeadura (DAS) das plantas de cobertura e a segunda época de poda na videira foi realizada aos 55 DAS. Cada parcela de $9 \mathrm{~m}^{2}$ ( 2 x 4,5 m), continham duas plantas de videira.

$\mathrm{O}$ experimento foi conduzido em dois períodos de safras. O período chamado de "safra de inverno" foi iniciado em fevereiro e finalizado em agosto de 2013, o período chamado de "safra de verão" foi de agosto de 2013 até fevereiro de 2014. Na safra de inverno as podas da videira foram realizadas nos dias 02 de março de 2013 (primeira poda, 25 DAS) e 01 de abril de 2013 (segunda poda, 55 DAS) empregando-se a poda longa, mantendo cinco gemas por vara. Na safra de verão as podas da videira foram realizadas nos dias 31 de agosto de 2013 (primeira poda, 25 DAS) e 30 de setembro de 2013 (segunda poda, 55 DAS) empregando-se a poda curta, mantendo duas gemas por vara. Após cada poda realizou-se a superação de dormência, das gemas, com Cianamida hidrogenada $\left(\right.$ Dormex $^{\circledR}$ a $5 \%$ ), aplicada com auxílio de rolo de espuma.

Foram avaliados três ciclos das plantas de cobertura, no primeiro ciclo a semeadura foi realizada em 5 de fevereiro de 2013, no segundo ciclo avaliouse a rebrota dessas plantas após seu manejo (roçagem dia 06 de abril de 2013) e no terceiro ciclo realizouse nova semeadura em 06 de agosto de 2013, com acompanhamento do seu desenvolvimento até

Tabela 1. Características químicas e físicas do solo, na profundidade de 0,0 a 0,20 m, da área experimental, antes da instalação do experimento.

Table 1. Chemical and physical characteristics of the soil, in the depth of 0,0 to 0,20 $\mathrm{m}$, of the experimental area, before the installation of the experiment.

\begin{tabular}{ccccccccccccc}
\hline $\begin{array}{c}\mathrm{pH} \\
\mathrm{CaCl}_{2}\end{array}$ & $\begin{array}{c}\text { M.O. } \\
(\%)\end{array}$ & $\begin{array}{c}\mathrm{P} \\
\left(\mathrm{mg} \mathrm{dm}^{-3}\right)\end{array}$ & $\mathrm{K}$ & $\mathrm{Ca}$ & $\mathrm{Mg}$ & $\mathrm{Al}$ & $\mathrm{H}+\mathrm{Al}$ & $\mathrm{CTC}$ & Argila & Silte & Areia \\
\hline 6,2 & 3,8 & 3,8 & 0,27 & 5,6 & 2,6 & 0,0 & 1,7 & 9,2 & 81,5 & 44 & 18 & 38 \\
\hline
\end{tabular}

M.O. = Matéria orgânica; V\% = saturação de bases.

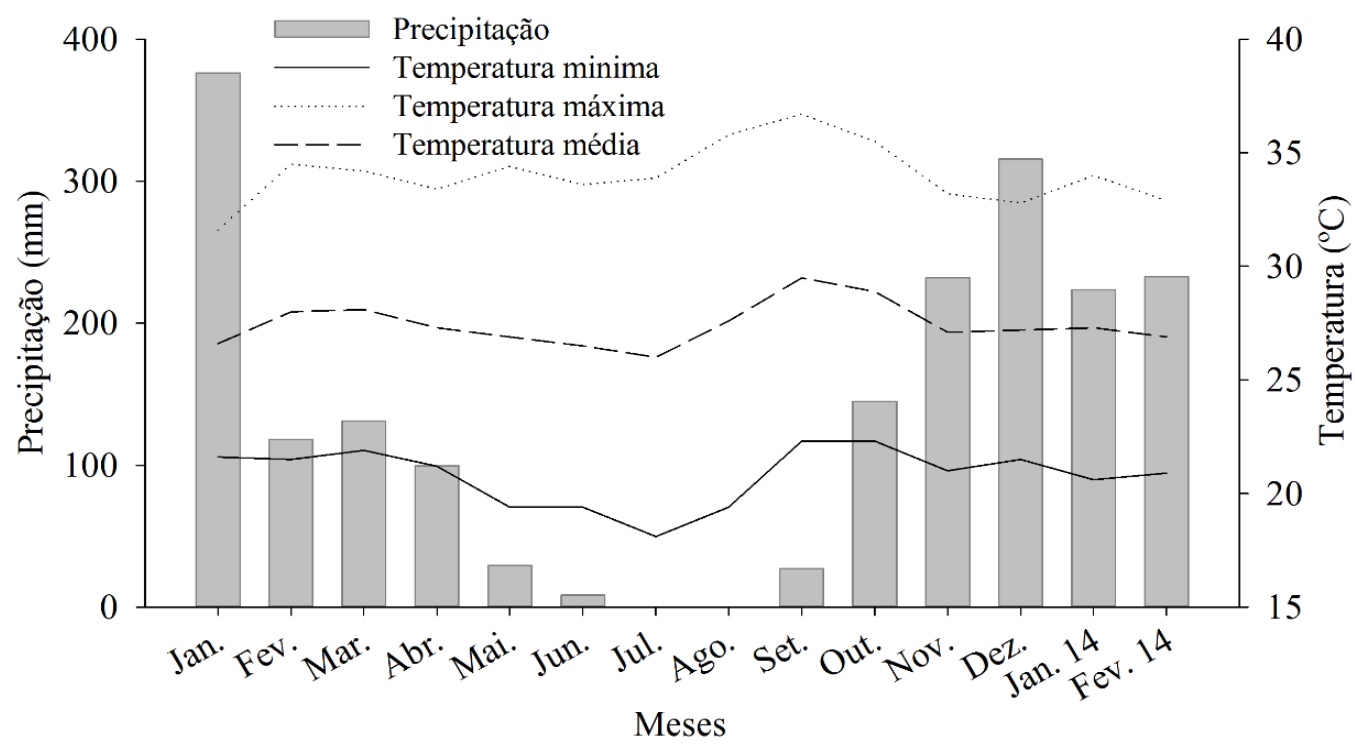

Figura 1. Precipitação pluviométrica, temperatura máxima, mínima e média mensais, no período do experimento. Figure 1. Rainfall, maximum, minimum and average monthly temperatures, in the period of the experiment. 
60 dias após a semeadura. Antes das semeaduras foi realizado controle químico das plantas espontâneas existentes em todas as parcelas, utilizando-se $3 \mathrm{~L} \mathrm{ha}^{-1}$ de glifosato. A semeadura foi feita em sulcos, com espaçamento de $0,45 \mathrm{~m}$ e profundidade aproximada de 1 a $2 \mathrm{~cm}$, realizada manualmente, utilizando cinco sementes de feijão-de-porco e dez de lab-lab, por metro e não se realizou adubação de plantio e inoculação das sementes.

As parcelas compostas pela cobertura com plantasespontâneasapresentaramasseguintesespécies, predominantes no primeiro ciclo: Picão-preto (Bidens pilosa L.) > Capim-colchão (Digitaria horizontalis Willd.) > Leiteira (Euphorbia heterophylla L.) > Trapoeraba (Commelina benghalensis L.) > Botãode-ouro (Siegesbeckia orientalis L.). No terceiro ciclo foram: Picão-preto (Bidens pilosa L.) > Capimcolchão (Digitaria horizontalis Willd.) $>$ carurugigante (Amaranthus retroflexus L.) $>$ vassoura (Sida rhombifolia L) > Leiteira (Euphorbia heterophylla L.) > Trapoeraba (Commelina benghalensis L.), no segundo ciclo a composição de plantas espontâneas não foi avaliada.

Os tratos culturais no parreiral, na safra de inverno, foram: adubação com $35 \mathrm{~g}_{\text {planta }}{ }^{-1}$ de $\mathrm{P}_{2} \mathrm{O}_{5}$ (superfosfato simples), dez dias antes da poda, $20 \mathrm{~g}$ planta $^{-1}$ de N (uréia), aos 15 e 45 dias após a poda, 25 g planta $^{-1}$ de FTE BR12, aos 15 dias após a poda e $15 \mathrm{~g}_{\text {planta }^{-1}}$ de $\mathrm{K}_{2} \mathrm{O}$, (cloreto de potássio), aos 80 dias após a poda. Os tratos culturais na safra de verão foram: adubação com 8, 60 e $20 \mathrm{~g} \mathrm{planta}^{-1}$ de $\mathrm{N}, \mathrm{P}_{2} \mathrm{O}_{5} \mathrm{e}$ $\mathrm{K}_{2} \mathrm{O}$, respectivamente, como fonte o formulado 4-3010, dez dias antes da poda, 20 g planta $^{-1}$ de $\mathrm{N}$ (uréia), aos 15 e 45 dias após a poda e $15 \mathrm{~g}$ planta $^{-1}$ de $\mathrm{K}_{2} \mathrm{O}$ (cloreto de potássio), aos 80 dias após a poda.

As plantas de videira foram avaliadas quanto a seu desenvolvimento, no período de pleno florescimento, pelas variáveis: diâmetro de ramos, comprimento de ramos e percentagem de brotação. O diâmetro de ramos foi medido com auxílio de paquímetro, o comprimento de ramos com auxílio de trena e a percentagem de brotação foi calculada pela relação entre o número de gemas brotadas e o número total de gemas deixadas no momento da poda.

$\mathrm{Na}$ ocasião da colheita foi avaliada a produtividade e as variáveis associadas: número de cachos por planta, massa média de cacho, comprimento e largura de cacho, número de bagas por cacho, comprimento, largura e massa de baga.

A produtividade $\left(\mathrm{kg} \mathrm{ha}^{-1}\right)$ foi obtida dividindo- se a produção da parcela pelo número de plantas por parcela, e posteriormente multiplicou-se pelo número de plantas por hectare, de acordo com o espaçamento adotado.

Para o número de cachos por planta fez-se a contagem de todos os cachos da parcela dividindo pelo número de plantas por parcela. A massa de cachos foi obtida dividindo a produção por parcela pelo número de cachos. O número de bagas por cacho foi obtido da contagem de todas as bagas em quatro cachos, por parcela.

O comprimento e largura dos cachos foram mensurados com paquímetro digital, em quatro cachos por parcela (SATO et al. 2009). Para o comprimento, largura e massa de baga coletaram-se dez bagas, aleatoriamente, por parcela, sendo o comprimento e altura de bagas determinados com paquímetro digital. A massa de dez bagas foi determinada em balança de precisão $(0,001 \mathrm{~g})$, obtendo-se a média por baga.

As bagas foram destacadas dos engaços, amostrando-se, ao acaso, dez bagas por cacho, totalizando 40 bagas por parcela. Estas foram trituradas, extraindo-se o suco para as determinações analíticas, com três repetições, dos seguintes atributos de qualidade: teor de sólidos solúveis (SS), expresso em ${ }^{\circ}$ Brix, $\mathrm{pH}$ e acidez titulável (AT), expressa em $\mathrm{g}$ de ácido tartárico por $100 \mathrm{ml}^{-1}$ de suco, conforme normas analíticas do IAL (2008). Calculou-se também a relação SS/AT.

O teor de sólidos solúveis foi determinado em refratômetro digital de bancada, ajustado à temperatura ambiente. A acidez titulável foi determinada por meio de titulação, de massa conhecida (10 g) do suco, com solução padronizada de hidróxido de sódio $(\mathrm{NaOH})$ a $0,1 \mathrm{M}$, tendo como indicador solução de fenolftaleína a $1 \%$. O potencial hidrogeniônico $(\mathrm{pH})$ foi determinado com auxílio de potenciômetro de $\mathrm{pH}$ digital, de bancada, calibrado com soluções tampão, $\mathrm{pH} 4,0$ e $\mathrm{pH} 7,0$.

Os dados foram submetidos à análise de variância pelo teste $\mathrm{F}$ e as médias comparadas pelo teste de Tukey com 5\% de probabilidade de erro utilizando-se o programa estatístico Sisvar 5.6 (FERREIRA 2014).

\section{RESULTADOS E DISCUSSÃO}

As plantas de cobertura do solo não influenciaram, significativamente, nenhuma das variáveis morfológicas analisadas, nas duas safras 
avaliadas (Tabela 2). Resultados diferentes, quanto ao uso de plantas de cobertura em cultivo de videiras, foram encontrados por ZALAMENA et al. (2013b), no planalto Sul Catarinense, verificando que as videiras consorciadas com as sucessões de espécies anuais de plantas de cobertura, apresentaram maior comprimento de entrenó dos ramos e maior produção de matéria seca, comparativamente às videiras do tratamento-testemunha (plantas espontâneas) e aquelas sob consórcio com a espécie perene. Segundo os autores, as videiras consorciadas com a planta de cobertura perene apresentaram ramos com menor comprimento, comparativamente às do tratamentotestemunha e as consorciadas com as sucessões de espécies anuais.

WHEELER et al. (2005) também verificaram menor vigor da videira, consorciada com chicória (Chicorium intybus L. var. sativum DC, 'Puna') (Asteraceae), o que foi atribuído à menor disponibilidade de água e nutrientes no solo, causado, primeiro, pelo hábito perene da planta de cobertura, mas especialmente ao grande volume de solo explorado pelas raízes daquela espécie de planta de cobertura, que possibilita maior absorção de água e nutrientes.

Com relação às épocas de poda, verificou-se efeito significativo. As variáveis estudadas mostramse superiores na primeira poda, nas duas safras, exceto para a percentagem de gemas brotadas, na safra de verão (Tabela 2). Resultados diferentes foram relatados BARTH et al. (2006) que não verificaram significância para o vigor dos ramos em diferentes épocas de poda na videira Niágara rosada, as podas foram realizadas em 17 de julho, 14 de agosto e 28 de agosto, em clima temperado.

Visualmente no campo foi constatado um menor desenvolvimento das plantas, da segunda época de poda em ambas as safras, inverno e verão, confirmado pela análise de médias (Tabela 2). No verão, por ser um período de chuvas intensas, as plantas da segunda poda, permaneceram por um maior tempo em repouso de janeiro a abril de 2013, com 90 dias de descanso desde o final da colheita, quando o normal seria de 30 a 40 dias de descanso, o que explicaria o baixo desenvolvimento. Já na safra de inverno, as médias mais baixas para a segunda poda se deu em virtude da maior percentagem de brotação (Tabela 2), o que causaria uma maior competição entre os brotos.

Segundo BOLIANI \& CORRÊA (2001) a atividade vegetativa do broto ou ramo, depende, de sua posição na vara, sendo as gemas mais próximas das pontas as de maiores privilégios e de sua direção, de modo que as mais verticais crescem mais.

A incidência de Míldio (Plasmopara viticola) nas plantas também pode ter contribuído para o baixo desenvolvimento depois da poda, pois o

Tabela 2. Diâmetro de ramos, comprimento de ramos e percentagem de gemas brotadas, no período de florescimento da videira Isabel, em consórcio com plantas de cobertura e duas épocas de poda.

Table 2. Branches diameter, length of branches and percentage of buds sprouted, during the flowering period of the Isabel vine, in consortium with cover plants and two pruning seasons.

\begin{tabular}{|c|c|c|c|c|c|c|c|c|c|}
\hline \multirow{2}{*}{ Variáveis } & \multirow{2}{*}{ Safra } & \multicolumn{2}{|c|}{ Épocas de poda } & \multirow{2}{*}{$\mathrm{F}$} & \multicolumn{3}{|c|}{ Plantas de cobertura } & \multirow{2}{*}{ DMS } & \multirow{2}{*}{$\mathrm{CV}(\%)$} \\
\hline & & $1^{\mathrm{a}}(25 \mathrm{DAS})$ & $2^{\mathrm{a}}(55 \mathrm{DAS})$ & & LB & FP & ES & & \\
\hline \multirow{2}{*}{ Diâmetro de ramos (mm) } & Inverno & 5,70 & 5,30 & $7,37^{*}$ & 5,60 & 5,60 & 5,30 & 0,56 & 9,09 \\
\hline & Verão & 5,80 & 5,40 & $9,65^{* *}$ & 5,60 & 5,80 & 5,50 & 0,41 & 6,52 \\
\hline \multirow{2}{*}{ Comprimento de ramos $(\mathrm{cm})$} & Inverno & 73,40 & 61,60 & $7,89^{*}$ & 70,00 & 68,80 & 63,50 & 13,03 & 17,07 \\
\hline & Verão & 68,40 & 60,10 & $7,96^{*}$ & 65,10 & 66,90 & 60,80 & 9,06 & 12,45 \\
\hline \multirow{2}{*}{ Gemas brotadas (\%) } & Inverno & 53,70 & 24,30 & $149,66^{* *}$ & 40,80 & 39,20 & 37,20 & 7,50 & 16,96 \\
\hline & Verão & 91,70 & 95,70 & $6,18^{*}$ & 91,50 & 95,50 & 94,00 & 4,98 & 4,70 \\
\hline
\end{tabular}

Médias seguidas por letras diferentes, na linha, diferem entre si $(\mathrm{p}<0,05)$ pelo teste de Tukey. A ausência de letras indica que não houve diferença significativa. $* *$ Significativo $(\mathrm{p}<0,01)$. ${ }^{*}$ Significativo $(\mathrm{p}<0,05)$. ns: não significativo. DAS $=$ Dias após a semeadura. $\mathrm{LB}=$ Lab-lab. FP = Feijão-de-porco. $\mathrm{ES}=$ plantas espontâneas. 
desfolhamento provocado pela doença, no período de repouso, foi elevado nas duas safras. Plantas apresentando folhas com alta intensidade de míldio, normalmente, manifestam desfolha acentuada, resultando na redução das taxas de reservas de carboidratos na planta, comprometendo a fertilidade de gemas e consequentemente, a produção da safra seguinte (AMORIM \& KUNIYUKI 1997). Portanto o manejo adequado do parreiral deve priorizar um bom estado nutricional e sanitário da videira, garantindo o acúmulo de reservas necessárias para o crescimento vegetativo da videira.

A produtividade da videira não foi afetada pelas plantas de cobertura do solo, em ambas as safras (Tabela 3). Resultados diferentes foram encontrados por ZALAMENA et al. (2013a) em consórcio da videira com espécies anuais de plantas de cobertura, que aumentaram a produtividade de uva. Entretanto FARIA et al. (2004) não verificaram efeitos positivos na produtividade, ao longo de oito safras de videiras consorciadas Crotalaria juncea e feijão-de-porco.

Dentre as variáveis associadas à produtividade apenas o diâmetro de bagas foi significativo na safra de verão. $O$ feijão-de-porco proporcionou maior diâmetro de bagas não diferindo, porém, das plantas espontâneas, que por sua vez não diferiu do lab-lab (Tabela 3). Pode-se observar que, de maneira geral, os componentes de produtividade foram melhores na safra de verão, isto se deve provavelmente à menor incidência de Míldio, pois a poda nesse período não é afetada pela frequência de chuvas (Figura 1).

$\mathrm{Na}$ safra de inverno as plantas foram submetidas à poda longa, com objetivo de frutificação, no entanto a produtividade foi menor se comparada à safra de verão, em que as plantas foram submetidas à poda curta (poda de formação). Isto pode ser atribuído ao fato de que na safra de inverno, houve precipitação nos meses de março a maio de 2013 (Figura 1), que proporcionou condições para a alta incidência de Míldio (Plasmopara viticola), afetando as inflorescências. Situação semelhante foi relatada por FARIA et al. (2004) em avaliação de plantas de cobertura no Submédio São Francisco.

Comparando-se as duas épocas de podas, observou-se efeitos significativos das variáveis produtividade, número de cachos por planta, massa de cacho, comprimento de cacho, diâmetro de baga e massa de baga (Tabela 3). A primeira poda, da safra de inverno, proporcionou maior produtividade e número de cachos por planta. Esses resultados podem estar ligados ao resultado da percentagem de brotação (Tabela 2), em que a primeira poda foi superior à segunda, pois com maior número de brotos se tem maior número de cachos, consequentemente maior será a produção. Essa relação se confirmou na safra de verão, ocorrendo o inverso, ou seja, menor número de cachos na primeira poda, sendo essa a que se obteve menor percentagem de brotação (Tabela 2). Segundo LEÃO \& RODRIGUES (2009) a fertilidade de gemas é uma característica muito influenciada pelo genótipo, ou seja, com comportamento diferenciado entre as cultivares, mas que pode sofrer grandes variações numa mesma cultivar, de um ciclo para outro, dependendo das condições climáticas ou, ainda, em um mesmo ciclo, de um local para outro, de acordo com diferenças no manejo das plantas.

$\mathrm{Na}$ safra de verão a massa de cacho, comprimento do cacho e massa de baga foi superior na primeira poda (Tabela 3). Tal acontecimento pode ser explicado porque na segunda poda de verão as brotações apresentaram grande número de cachos, evidenciado na análise de médias, o que pode acarretar em um baixo desenvolvimento dos mesmos, pela maior competição, como relatado por BORGHEZAN et al. (2011).

As plantas de cobertura do solo não influenciaram as características qualitativas da uva Isabel, em ambas as safras avaliadas (Tabela 4). FARIA et al. (2004) também não observaram efeito consistente da adubação verde sobre a qualidade de uva, no Submédio São Francisco. ZALAMENA et al. (2013a) também verificaram que a composição da uva não é afetada pelo consórcio, com plantas de cobertura, em duas safras avaliadas na Serra Catarinense.

Para as épocas de poda houve efeito significativo para o $\mathrm{pH}$, acidez titulável e relação SS/ AT, na safra de inverno. A primeira poda apresentou de maneira geral melhor qualidade, com $\mathrm{pH}$ mais elevado e acidez titulável mais baixa, e o índice de maturação superior ao da segunda poda (Tabela 4). NEIS et al. (2010) observaram para a videira Niágara Rosada, podada em quatro diferentes épocas do ano no sudoeste Goiano, que as características organolépticas dos frutos foram adequadas, evidenciando, assim, o potencial de produção de uvas de qualidade na região.

Os valores de sólidos solúveis, encontrados no mosto de uva nas duas safras, para os tratamentos com as plantas de cobertura ficaram abaixo dos padrões exigidos pela Legislação Brasileira (BRASIL 2000), em que o teor mínimo exigido é de $14{ }^{\circ}$ Brix. 
Tabela 3. Produtividade e variáveis associadas, da videira Isabel, em consórcio com plantas de cobertura e duas épocas de poda.

Table 3. Productivity and associated variables of the Isabel vine, in consortium with cover crops and two pruning seasons.

\begin{tabular}{|c|c|c|c|c|c|c|c|c|c|}
\hline \multirow[b]{2}{*}{ Variáveis } & \multirow[b]{2}{*}{ Safra } & \multicolumn{2}{|c|}{ Épocas de poda } & & \multicolumn{3}{|c|}{ Plantas de cobertura } & \multirow[b]{2}{*}{ DMS } & \multirow[b]{2}{*}{$\mathrm{CV}(\%)$} \\
\hline & & $\begin{array}{l}1^{\mathrm{a}}(25 \\
\mathrm{DAS})\end{array}$ & $\begin{array}{l}2^{\mathrm{a}}(55 \\
\mathrm{DAS})\end{array}$ & & LB & $\mathrm{FP}$ & ES & & \\
\hline \multirow{2}{*}{ Produtividade $\left(\mathrm{t} \mathrm{ha}^{-1}\right)$} & Inverno & 1,13 & 4,58 & $9,63^{* *}$ & 0,92 & 0,74 & 0,72 & 0,67 & 46,25 \\
\hline & Verão & 4,67 & 5,62 & $1,02^{\mathrm{ns}}$ & 5,57 & 4,81 & 5,05 & 2,91 & 50,02 \\
\hline \multirow{2}{*}{$\mathrm{N}^{\mathrm{o}}$ de cachos/planta } & Inverno & 34,00 & 11,32 & $16,78^{* *}$ & 25,59 & 21,50 & 20,90 & 15,61 & 36,22 \\
\hline & Verão & 45,76 & 80,80 & $19,53^{* *}$ & 64,75 & 63,80 & 61,30 & 24,57 & 34,30 \\
\hline \multirow{2}{*}{ Massa de Cacho (g) } & Inverno & 18,80 & 22,10 & $1,82^{\mathrm{ns}}$ & 20,63 & 21,30 & 19,41 & 7,56 & 32,68 \\
\hline & Verão & 62,76 & 42,03 & $15,68^{* *}$ & 53,92 & 48,91 & 54,35 & 16,23 & 27,36 \\
\hline \multirow{2}{*}{$\begin{array}{l}\text { Comprimento de } \\
\text { cacho (mm) }\end{array}$} & Inverno & 75,18 & 65,63 & $2,90^{\mathrm{ns}}$ & 73,47 & 72,26 & 65,48 & 17,37 & 21,79 \\
\hline & Verão & 89,77 & 82,13 & $14,13^{* *}$ & 84,07 & 87,30 & 86,49 & 6,30 & 6,48 \\
\hline \multirow{2}{*}{$\begin{array}{l}\text { Largura de cacho } \\
\qquad(\mathrm{mm})\end{array}$} & Inverno & 54,30 & 47,56 & $3,56^{\mathrm{ns}}$ & 53,00 & 50,83 & 48,96 & 11,07 & 19,21 \\
\hline & Verão & 60,33 & 57,70 & $3,39^{\text {ns }}$ & 58,39 & 60,61 & 58,05 & 4,42 & 6,62 \\
\hline \multirow{2}{*}{$\mathrm{N}^{\mathrm{o}}$ de bagas/cacho } & Inverno & 14,18 & 12,29 & $0,91^{\mathrm{ns}}$ & 13,44 & 13,60 & 12,67 & 6,13 & 40,92 \\
\hline & Verão & 20,03 & 18,55 & $2,29^{\text {ns }}$ & 18,00 & 19,27 & 20,60 & 3,03 & 13,90 \\
\hline \multirow{2}{*}{$\begin{array}{l}\text { Comprimento de baga } \\
\qquad(\mathrm{mm})\end{array}$} & Inverno & 17,61 & 17,09 & $2,94^{\mathrm{ns}}$ & 17,05 & 17,46 & 17,54 & 0,92 & 4,71 \\
\hline & Verão & 17,49 & 17,11 & $3,73^{\text {ns }}$ & 17,55 & 17,37 & 16,98 & 0,60 & 3,10 \\
\hline \multirow{2}{*}{$\begin{array}{l}\text { Diâmetro de baga } \\
\qquad(\mathrm{mm})\end{array}$} & Inverno & 15,77 & 15,41 & $1,27^{\mathrm{ns}}$ & 15,57 & 15,55 & 15,64 & 0,97 & 5,53 \\
\hline & Verão & 17,49 & 18,82 & $44,21^{* *}$ & $17,85 \mathrm{~b}$ & $18,50 \mathrm{a}$ & $18,13 \mathrm{ab}$ & 0,61 & 3,01 \\
\hline \multirow{2}{*}{ Massa de baga (g) } & Inverno & 3,01 & 3,04 & $0,03^{\mathrm{ns}}$ & 2,91 & 3,08 & 3,09 & 0,43 & 12,60 \\
\hline & Verão & 4,10 & 3,90 & $6,19^{*}$ & 4,02 & 4,07 & 3,91 & 0,25 & 5,61 \\
\hline
\end{tabular}

Médias seguidas por letras diferentes, na linha, diferem entre si $(\mathrm{p}<0,05)$ pelo teste de Tukey. ${ }^{* *}$ significativo $(\mathrm{p}<0,01)$. *Significativo $(\mathrm{p}<0,05) . \mathrm{DAS}=$ Dias após a semeadura. $\mathrm{LB}=$ Lab-lab. FP $=$ Feijão-de-porco. $\mathrm{ES}=$ plantas espontâneas.

Para os tratamentos das épocas de poda, apenas os valores da segunda poda, nas duas safras alcançaram o valor mínimo (Tabela 4). Segundo RIZZON \& MENEGUZZO (2007) entre as cultivares do grupo das americanas, a cultivar Isabel apresenta elevado potencial de acúmulo de açúcar na baga, podendo variar, em função das safras, entre $14^{\circ}$ Brix a 18 ${ }^{\circ}$ Brix. No Sul do Brasil a uva Isabel pode chegar ao teor de sólidos solúveis de $18,4^{\circ}$ Brix (CAMARGO \& NACHTIGAL 2007). Na região nordeste do Brasil, na Zona da Mata do Estado de Pernambuco foram observadas $14,6{ }^{\circ}$ Brix e acidez titulável de 0,72\% de ácido tartárico, no Submédio do Vale do São Francisco, a cultivar Isabel, conduzida em espaldeira, apresentou $16,5^{\circ}$ Brix até $17,2^{\circ}$ Brix e acidez titulável de $0,56 \%$ a $0,79 \%$ de ácido tartárico (LEÃO et al.
2009).

Pode-se associar o baixo teor de sólidos solúveis, menor que $14{ }^{\circ}$ Brix, verificado nesse experimento, ao desfolhamento ocorrido nas videiras, em virtude da alta incidência de Míldio. BRIGHENTI et al. (2010) observaram que o teor de sólidos solúveis nas uvas está associado à maior atividade fotossintética, derivada do aumento da área foliar da videira. Segundo ZALAMENA et al. (2013a) em certas situações, a desfolha ao redor dos cachos pode retardar a maturação, pois o menor número de folhas por planta causa a diminuição da produção de fotoassimilados para os cachos, conforme relatado por PÖTTER et al. (2010), o que reduziria o $\mathrm{pH}$ e aumentaria o teor de acidez total no mosto. Dessa forma, a elevada incidência de doenças fúngicas, ao 
Tabela 4. Sólidos solúveis, pH, acidez titulável e relação SS/AT, da uva Isabel, em consórcio com plantas de cobertura e duas épocas de poda.

Table 4. Soluble solids, $p H$, titratable acidity and SS/AT ratio of Isabel grape, in consortium with cover crops and two pruning seasons.

\begin{tabular}{|c|c|c|c|c|c|c|c|c|c|}
\hline \multirow{2}{*}{ Variáveis } & \multirow{2}{*}{ Safra } & \multicolumn{2}{|c|}{ Épocas de poda } & & \multicolumn{3}{|c|}{ Plantas de cobertura } & \multirow{2}{*}{ DMS } & \multirow{2}{*}{$\mathrm{CV}(\%)$} \\
\hline & & $1^{\mathrm{a}}(25 \mathrm{DAS})$ & $2^{\mathrm{a}}(55 \mathrm{DAS})$ & & LB & FP & ES & & \\
\hline \multirow{2}{*}{$\mathrm{pH}$} & Inverno & 3,06 & 3,10 & $4,63^{*}$ & 3,08 & 3,08 & 3,07 & 0,05 & 1,71 \\
\hline & Verão & 2,61 & 2,64 & $1,35^{\mathrm{ns}}$ & 2,63 & 2,62 & 2,63 & 0,06 & 2,27 \\
\hline \multirow{2}{*}{$\begin{array}{l}\text { Sólidos } \\
\text { solúveis } \\
\text { ( }{ }^{\circ} \text { Brix) }\end{array}$} & Inverno & 13,52 & 14,35 & $1,19^{\mathrm{ns}}$ & 14,80 & 13,75 & 13,59 & 2,34 & 14,84 \\
\hline & Verão & 13,34 & 13,99 & $3,28^{\mathrm{ns}}$ & 13,76 & 13,45 & 13,80 & 1,09 & 7,05 \\
\hline \multirow{2}{*}{$\begin{array}{l}\text { Acidez } \\
\text { titulável }\end{array}$} & Inverno & 0,86 & 1,24 & $69,94^{* *}$ & 1,00 & 1,04 & 1,10 & 0,14 & 11,87 \\
\hline & Verão & 0,86 & 0,91 & $2,04^{\mathrm{ns}}$ & 0,90 & 0,88 & 0,89 & 0,10 & 10,74 \\
\hline \multirow{2}{*}{$\mathrm{SS} / \mathrm{AT}$} & Inverno & 15,78 & 11,86 & $19,60^{* *}$ & 15,08 & 13,46 & 12,91 & 2,74 & 17,54 \\
\hline & Verão & 15,43 & 15,47 & $0,002^{\mathrm{ns}}$ & 15,27 & 15,51 & 15,57 & 2,43 & 14,11 \\
\hline
\end{tabular}

Médias seguidas por letras diferentes, na linha, diferem entre si $(\mathrm{p}<0,05)$ pelo teste de Tukey. A ausência de letras indica que não houve diferença significativa. **Significativo $(p<0,01) . *$ Significativo $(p<0,05)$. ns: não significativo. $\mathrm{DAS}=$ Dias após a semeadura. $\mathrm{LB}=\mathrm{Lab}-\mathrm{lab} . \mathrm{FP}=$ Feijão-de-porco. $\mathrm{ES}=$ plantas espontâneas.

excesso de água no solo (na época da colheita da safra de verão) e a outros fatores climáticos impedem que a uva atinja a completa maturação, comprometendo a sua qualidade (REGINA et al. 2006).

Segundo a Legislação Brasileira polpa de uva deverá obedecer às características e composição, quanto ao teor de $\mathrm{pH}$ de 2,9 no mínimo e 0,41 g/ $100 \mathrm{~g}$ de ácido tartárico, no mínimo, para acidez total (BRASIL 2000). Na safra de verão os valores de $\mathrm{pH}$ ficaram abaixo do mínimo estabelecido, independente dos tratamentos com plantas de cobertura e épocas de poda. SATO et al. (2009) verificaram que a evolução do $\mathrm{pH}$ apresenta comportamento inverso à evolução da acidez. Este resultado pode ser explicado pelo fato do aumento do $\mathrm{pH}$ nas bagas estar relacionado à salinificação dos ácidos orgânicos e ao aumento do cátion potássio (MANFROI et al. 2004).

A relação SS/AT representa o equilíbrio entre o gosto doce e ácido do suco de uva, portanto, um indicativo de qualidade de suco de uva (PEZZI \& FENOCCHIO 1976). A Legislação Brasileira estabelece os limites da relação SS/AT entre 15 e 45 (BRASIL 2000). Os valores mais elevados representam sucos de uva menos ácidos. Neste estudo a relação mais alta atingida foi de 15,78 na primeira poda de inverno e 15,57 para tratamento com as plantas espontâneas na safra de verão (Tabela 4), isso índica que as uvas apresentaram elevada acidez, nesse caso seriam reprovadas para produção de suco, ou teriam baixa aceitação pelos consumidores, para consumo in natura.

Uma explicação para essa maior acidez (principalmente na safra de verão) e baixa relação SS/ AT, pode ser atribuída ao maior número de cachos, produzidos por planta (Tabela 3). Segundo SATO et al. (2009) nem sempre as grandes quantidades de cachos são interessantes quando se deseja uvas para elaboração de sucos, pois quanto maior o número de cachos, menor será a distribuição de carboidratos para os mesmos, o que pode prejudicar a qualidade da uva e consequentemente o seu suco.

\section{CONCLUSÕES}

Em três ciclos de cultivo, as plantas de cobertura do solo consorciadas com a videira, não influenciam as variáveis morfológicas, a produtividade, as variáveis associadas a produtividade e as características qualitativas da uva.

Diferentes épocas de poda influenciam a produtividade e as variáveis associadas na cultura da videira.

A poda aos 25 dias após a semeadura, das plantas de cobertura, apresenta melhores resultados para as variáveis morfológicas e características qualitativas da uva. 


\section{AGRADECIMENTOS}

A Fundação de Amparo à Pesquisa do Estado de Goiás pelo financiamento, sob o número de concessão 2013102671038.

\section{REFERÊNCIAS}

ABREU CM et al. 2017. Produtividade e qualidade de frutos de videira 'Isabel' em função das doses de etefon e épocas de poda. Revista de Agricultura Neotropical 4: 1220.

AMORIM L \& KUNIYUKI H. 1997. Doenças da videira (Vitis spp). In: KIMATI $\mathrm{H}$ et al. (Eds.). Manual de fitopatologia: doenças das plantas cultivadas. 3.ed. São Paulo: Agronômica Ceres. p. 732-757.

BARTH CV et al. 2006. Expressão da fertilidade de gemas da videira em função de diferentes épocas de poda e doses de nitrogênio. Scientia Agraria 7: 67-73.

BOLIANI AC \& CORRÊA LS. 2001. Cultura de uvas de mesa do plantio à comercialização. Ilha Solteira: ALGRAF. $328 \mathrm{p}$.

BORGHEZAN $\mathrm{M}$ et al. 2011. Comportamento vegetativo e produtivo da videira e composição da uva em São Joaquim, Santa Catarina. Pesquisa Agropecuária Brasileira 46: 398405.

BRASIL. 2000. Ministério da Agricultura e do Abastecimento. Instrução Normativa n. 01, de 07 de janeiro de 2000. Regulamento técnico geral para fixação dos padrões de identidade e qualidade para polpa de fruta. Diário Oficial da República Federativa do Brasil: Brasília. p. 54-58.

BRIGHENTI AF et al. 2010. Desponte dos ramos da videira e seu efeito na qualidade dos frutos de 'Merlot' sobre os porta enxertos 'Paulsen 1103' e 'Couderc 3309'. Revista Brasileira de Fruticultura 32: 19-26.

CAMARGO UA \& NACHTIGAL JC. 2007. Cultivares. In: NACHTIGAL JC \& SCHNEIDER EP. Recomendações para produção de videiras em sistemas de base ecológica. Bento Gonçalves: Embrapa Uva e Vinho. p. 11-17. (Documentos 65).

CAMARGO UA et al. 2012. Grapevine performance and production strategies in tropical climates. Asian Journal of Food and Agro-Industry 5: 257-269.

CAMPOS LFC et al. 2015. Plantas de cobertura do solo em área de videira rústica cultivada no cerrado goiano. Revista de Ciências Agrárias 58: 184-191.

COLUGNATI $G$ et al. 2004. Gestione del terreno in viticoltura. Vignevini 11: 54-84.

DAUDT CE \& FOGAÇA AO. 2008. Efeito do ácido tartárico nos valores de potássio, acidez titulável e pH durante a vinificação de uvas Cabernet Sauvignon. Ciência Rural 38: 2345-2350.

EMBRAPA. 2013. Sistema brasileiro de classificação de solos. 3.ed. Brasília: Embrapa. 353p.
FARIA CMB et al. 2004. Adubação verde com leguminosas em videira no Submédio São Francisco. Revista Brasileira de Ciência do Solo 28: 641-648.

FARIA SS et al. 2013. Produção de uvas como atividade inovadora da agricultura familiar no Estado de Goiás. Goiânia: Segplan/Instituto Mauro Borges 25: 66-77. (Conjuntura econômica goiana 2).

FERREIRA DF. 2014. Sisvar: a Guide for its Bootstrap procedures in multiple comparisons. Ciência e Agrotecnologia 38: 109-112.

IAL. INSTITUTO ADOLFO LUTZ. 2008. Normas analíticas do Instituto Adolfo Lutz: métodos químicos e físicos para análises de alimentos. 4.ed. São Paulo: IAL. $1020 \mathrm{p}$.

LEÃO PCS \& RODRIGUES BL. 2009. Manejo da copa. In: SOARES JM et al. (Eds.). A vitivinicultura no Semiárido brasileiro. Brasília: Embrapa Informação Tecnológica/ Petrolina: Embrapa Semiárido. p.293-348.

LEÃO PCS et al. 2009. Principais cultivares. In. SOARES $\mathrm{JM}$ et al. (Eds). A vitivinicultura no Semiárido brasileiro. Brasília: Embrapa Informação Tecnológica/Petrolina: Embrapa Semiárido. p.149-214.

LOPES CM et al. 2008. Cover cropping in a slopping nonirrigated vineyard: II - Effects on vegetative growth, yield, berry and wine quality of 'Cabernet Sauvignon' grapes. Ciência e Técnica Vitivinícola 23: 37-43.

MANFROI L et al. 2004. Evolução da maturação da uva Cabernet Franc conduzida no sistema lira aberta. Ciência e Agrotecnologia 28: 306-313.

MONTEIRO A et al. 2008. Cover cropping on a sloping, non-irrigated vineyard: I. Effects on weed composition and dynamics. Ciência e Técnica Vitivinícola 23: 29-36.

NEIS S et al. 2010. Produção e qualidade da videira cv. Niágara Rosada em diferentes épocas de poda no sudoeste goiano. Revista Brasileira de Fruticultura 32: 1146-1153.

PEZZI GM \& FENOCCHIO P. 1976. Estudo analítico dos sucos de uva comerciais. Pesquisa Agropecuária Brasileira 11: 11-13.

PÖTTER GH et al. 2010. Desfolha parcial em videiras e seus efeitos em uvas e vinhos Cabernet Sauvignon da região da Campanha do Rio Grande do Sul, Brasil. Ciência Rural 40: 2011-2016.

REGINA MA et al. 2006. Novos polos vitícolas para produção de vinhos finos em Minas Gerais. Informe Agropecuário. 27: 111-118.

RIZZON LA \& MENEGUZZO J. 2007. Suco de uva. Brasília: Embrapa Informação Tecnológica. 45p.

SATO AJ et al. 2009. Evolução da maturação e características físico-químicas de uvas da cultivar Isabel sobre diferentes porta-enxertos na Região Norte do Paraná. Semina: Ciências Agrárias 30: 11-20.

SILVA RP et al. 2006. Comportamento fenológico de videira, cultivar Patrícia em diferentes épocas de poda de frutificação em Goiás. Bragantia 65: 399-406.

WHEELER SJ et al. 2005. Vineyard floor management 
improves wine quality in highly vigorous Vitis vinifera 'Cabernet Sauvignon' in New Zealand. New Zealand Journal of Crop and Horticultural Science 33: 317-328.

WUTKE EB et al. 2004. Qualidade de frutos de videira 'Niágara rosada' em cultivo intercalar com gramínea e leguminosas. Revista Brasileira de Fruticultura 26: 92-96.

ZALAMENA J et al. 2013a. Produtividade e composição de uva e de vinho de videiras consorciadas com plantas de cobertura. Pesquisa Agropecuária Brasileira 48:182-189.

ZALAMENA J et al. 2013b. Estado nutricional, vigor e produção em videiras cultivadas com plantas de cobertura. Revista Brasileira de Fruticultura 35: 1190-1200. 